\title{
(C) OPEN ACCESS \\ Determinants of anxiety in elite athletes: a systematic review and meta-analysis
}

\author{
Simon M Rice, ${ }^{\oplus 1,2}$ Kate Gwyther, $^{\oplus 1,2}$ Olga Santesteban-Echarri, ${ }^{\circ}$ David Baron, $^{4}$ \\ Paul Gorczynski, ${ }^{5}$ Vincent Gouttebarge, $^{6,7}$ Claudia L Reardon, ${ }^{8,9}$ Mary E Hitchcock, ${ }^{10}$ \\ Brian Hainline, ${ }^{11}$ Rosemary Purcell ${ }^{1,2}$
}

- Additional material is published online only. To view please visit the journal online (http://dx.doi.org/10.1136/ bjsports-2019-100620).

For numbered affiliations see end of article.

\section{Correspondence to} Dr Simon M Rice, Research and Translation, Orygen, The National Centre of Excellence in Youth Mental Health, Melbourne, VIC 3052, Australia; simon.rice@orygen.org.au

Received 22 January 2019 Revised 13 March 2019 Accepted 14 March 2019

\section{Check for updates}

(C) Author(s) (or their employer(s)) 2019. Re-use permitted under CC BY-NC. No commercial re-use. See rights and permissions. Published by BMJ.

To cite: Rice SM, Gwyther K, Santesteban-Echarri 0, et al. Br J Sports Med 2019:53:722-730.

\begin{abstract}
Objective To identify and quantify determinants of anxiety symptoms and disorders experienced by elite athletes.

Design Systematic review and meta-analysis.

Data sources Five online databases (PubMed, SportDiscus, PsycINFO, Scopus and Cochrane) were searched up to November 2018 to identify eligible citations.
\end{abstract}

Eligibility criteria for selecting studies Articles were included if they were published in English, were quantitative studies and measured a symptom-level anxiety outcome in competing or retired athletes at the professional (including professional youth), Olympic or collegiate/university levels.

Results and summary We screened 1163 articles; 61 studies were included in the systematic review and 27 of them were suitable for meta-analysis. Overall risk of bias for included studies was low. Athletes and non-athletes had no differences in anxiety profiles $(d=-0.11, p=0.28)$. Pooled effect sizes, demonstrating moderate effects, were identified for (1) career dissatisfaction $(d=0.45$; higher anxiety in dissatisfied athletes), (2) gender $(d=0.38$; higher anxiety in female athletes), (3) age $(d=-0.34$; higher anxiety for younger athletes) and (4) musculoskeletal injury $(d=0.31$; higher anxiety for injured athletes). A small pooled effect was found for recent adverse life events $(d=0.26)$ - higher anxiety in athletes who had experienced one or more recent adverse life events.

Conclusion Determinants of anxiety in elite populations broadly reflect those experienced by the general population. Clinicians should be aware of these general and athlete-specific determinants of anxiety among elite athletes.

\section{INTRODUCTION}

Combined anxiety disorders affect the general population at an estimated (past 12 month) rate of $10.6 \%-12.0 \%,{ }^{12}$ with broadly similar rates suggested among elite athlete populations (8.6\%), ${ }^{3}$ defined as those competing at professional, Olympic or collegiate/university levels. Anxiety disorders are characterised by emotional responses associated with fear, apprehension, worry and tension in response to an actual or perceived threat. ${ }^{4}$ Anxiety modulates attentional networks, resulting in compromised executive function, stimulus processing and information selection ${ }^{5}$-all important domains for elite competition. While commonalities are present, diagnostic systems differentiate anxiety subtypes, such as generalised anxiety disorder
(GAD) or social anxiety disorder. ${ }^{4}$ Additionally, anxiety can be a situationally or event-dependent transitory state (eg, state anxiety), or a relatively stable personality characteristic (eg, trait anxiety). State anxiety symptoms are more likely to occur in situations perceived as threatening. ${ }^{6}$

Athlete-specific factors may precipitate or exacerbate anxiety disorders, including pressures to perform and public scrutiny, ${ }^{7}$ career uncertainty or dissatisfaction, ${ }^{89}$ and injury. ${ }^{10-12}$ General psychosocial factors are also strongly implicated in the onset and maintenance of anxiety disorders within the general population. These include behavioural inhibition, social withdrawal or avoidance, and cognitive patterns of rumination. ${ }^{13}$ A recent meta-analysis found that female gender, younger age and lower athletic experience were associated with higher competitive anxiety in athletes ${ }^{14}$; however, the specific determinants of anxiety disorders in elite athlete populations has not yet been reported. Identification of putative subgroup differences may assist with early identification and indicated prevention efforts in this population, improving the timely management of anxiety disorders among elite athletes. The objective of this study was to perform a systematic review and meta-analysis to identify, quantify and analyse determinants of anxiety symptoms experienced by elite athletes.

\section{METHOD}

The study was conducted in accordance with the Preferred Reporting Items for Systematic Reviews and Meta-Analyses guidelines.

\section{Search strategy}

A systematic search strategy was developed by an experienced academic librarian $(\mathrm{MEH})$. The search was executed in the PubMed, SportDiscus, PsycINFO, Scopus and Cochrane databases from inception until November 2018. The search strategy and $\mathrm{MeSH}$ terms are presented in online supplementary table 1 . Citations were independently screened by SMR, RP and KG.

\section{Study inclusion}

Studies were selected if they included (1) data on elite athletes, including para-athletes, defined by standard of performance level, ${ }^{15}$ competing at the professional (and professional youth, ie, members of elite sports schools), Olympic and collegiate/ university levels; (2) a symptomatic or diagnostic anxiety outcome measure (as per the Diagnostic and Statistical Manual of Mental Disorders [DSM-5] ${ }^{4}$ 
criteria) in relation to GAD, specific phobia, social anxiety, panic disorders or obsessive-compulsive disorder (OCD); and (3) currently competing or retired athletes (authors adopted a maximum mean retirement length of 10 years to allow investigation of effects between anxiety and longer-term sport-specific outcomes [eg, concussion], ${ }^{16}$ and account for, yet limit the effect of retirement). ${ }^{17}$

\section{Study exclusion}

Studies were excluded if they were not published in English, were a case study or case report, used a qualitative design, were review articles or were not refereed journal articles (conference abstracts were excluded), or focused solely on state-based performance or competitive anxiety (ie, included studies needed to report on a measure/diagnosis of symptom-level anxiety as per DSM-5).

\section{Assessment of study quality}

We assessed quality of studies with the Joanna Briggs Institute's critical appraisal tools for systematic reviews. ${ }^{18}$ These tools are validated appraisal checklists specific to study design, capturing aspects of design quality, analysis and reporting. KG assessed studies using checklists for randomised controlled trials (RCTs), cohort studies, prevalence studies, cross-sectional studies and quasi-experimental studies. The appraisal score reported is the proportion of 'yes' responses on the total number of criteria. If a criterion was not applicable (N/A) to a given study, that item was not counted in the total number of criteria.

\section{Data extraction}

A standard template was designed for data extraction of study and sample characteristics including study design, aim, location, gender ratio, sport population, anxiety outcome and key findings. KG extracted the data and SMR reviewed them for consistency. For the meta-analysis, KG extracted a list of determinants of anxiety (associated variables) in each study to assess viability for meta-analysis. Once a determinant was identified, KG extracted the relevant quantitative data, while OS-E and SMR reviewed for consistency.

\section{Data analysis (meta-analysis)}

Pooled effect sizes were estimated using Comprehensive Meta-Analysis (CMA) software V.3.3.070. ${ }^{19}$ Raw data (mean, SD and $n$ ) were sourced for determinants of anxiety. When raw data were unavailable, we used effect size data $(r, \mathrm{OR}, t, \beta$ and $F$ values). Overall effect sizes were estimated using the standardised difference in means $(d)$ because this could be calculated for all types of extracted data. When we could not enter effect size data directly into CMA (eg, $\beta, F$ and $t$ statistics), transformations were made into an $r$ statistic. ${ }^{2021}$ All meta-analyses used the random-effects model to account for within-study error and between-study variation. Though a minimum of two studies are needed to perform a meta-analysis, ${ }^{22} \mathrm{CMA}$ software requires at least three studies to perform publication bias analysis, ${ }^{23}$ hence we required three studies for inclusion in the overall (eg, non-subgroup) meta-analyses. An initial population comparison (elite athletes compared with non-athletes) was conducted, followed by analysis of the determinant variables.

\section{Subgroup and sensitivity analysis}

Where applicable, we conducted subgroup analysis to assess effect sizes across different anxiety outcomes (generalised, trait, diagnosis and global anxiety/depression) and playing status (current vs former). As subgroup analysis calculates an estimated effect size for each subgroup, a minimum of two subgroups with two contributing studies each were required to conduct a statistically sound analysis for a determinant. ${ }^{22}$ Additionally, sensitivity analysis was conducted when significant heterogeneity was observed. Sensitivity analysis is a repeat of the initial analysis which substitutes alternate inclusion or exclusion decisions to assess robustness of the results. ${ }^{24}$ Sensitivity analysis was calculated by removing any visual outliers or studies with dissimilar characteristics.

\section{Interpretation of forest plots}

A forest plot is a visual representation of the effect size for each study, represented by squares, and the overall estimated effect size, represented by a diamond. The side of the forest plot on which the effect size estimate falls indicates a higher anxiety score in that group. For plots with subgroup analysis, overall effect size estimates are reported in the text.

\section{Heterogeneity and publication bias}

The $Q$ statistic measured the presence or absence of heterogeneity by testing the null hypothesis of no variation in true effect size across studies. ${ }^{25}$ Heterogeneity was assumed when the $Q$ statistic was significant, as the null hypothesis of no variation is rejected. The $I^{2}$ statistic describes the proportion of variance in observed effects due to variance in true effects and can be interpreted as the percentage of variance that would remain if there was no sampling error. ${ }^{26}$ Low $I^{2}$ scores indicate lower heterogeneity. Publication bias was assessed using the Duval and Tweedie trim-and-fill funnel plot method. ${ }^{27} \mathrm{~A}$ funnel plot is a graphical representation of study size as a function of effect size; large studies generally appear at the top of the graph, close to the mean effect size, and small studies typically appear at the bottom of the graph, spread broadly around the mean effect size. ${ }^{28}$ Asymmetry in funnel plots (more studies falling to one side of the graph) indicates potential publication bias. To assess the scope of bias, the trim-and-fill method estimates the number of missing studies in an asymmetrical plot, balances it with the 'fill' of additional study points and recalculates the estimated effect size using the filled estimates. ${ }^{27}$

\section{RESULTS}

\section{Literature search}

The database search returned 1163 articles (figure 1). After removal of duplicates, 1111 articles were screened for eligibility. Of the resulting 145 eligible articles, 61 were included in the narrative synthesis after full-text assessment. These articles are listed and grouped by anxiety outcome measure in table 1 .

\section{Description of included studies}

Table 2 summarises the study characteristics of the reviewed articles (see online supplementary table 2 for a detailed summary of study characteristics for each article). Of the 61 studies, 46 (75\%) were published from 2014 onwards. Samples typically represented athletes from multiple countries $(n=16,26.2 \%)$. For single-location samples, the most common country was the USA ( $n=13,21.3 \%)$, followed by Australia, France, Germany and Ireland with three studies each (5.0\%). Italy, Korea, Spain, Sweden and Switzerland appeared twice (3.3\%), and Canada, China, Denmark, Egypt, Israel, Netherlands, Norway, Tunisia, Turkey and the UK appeared once (1.6\%). 


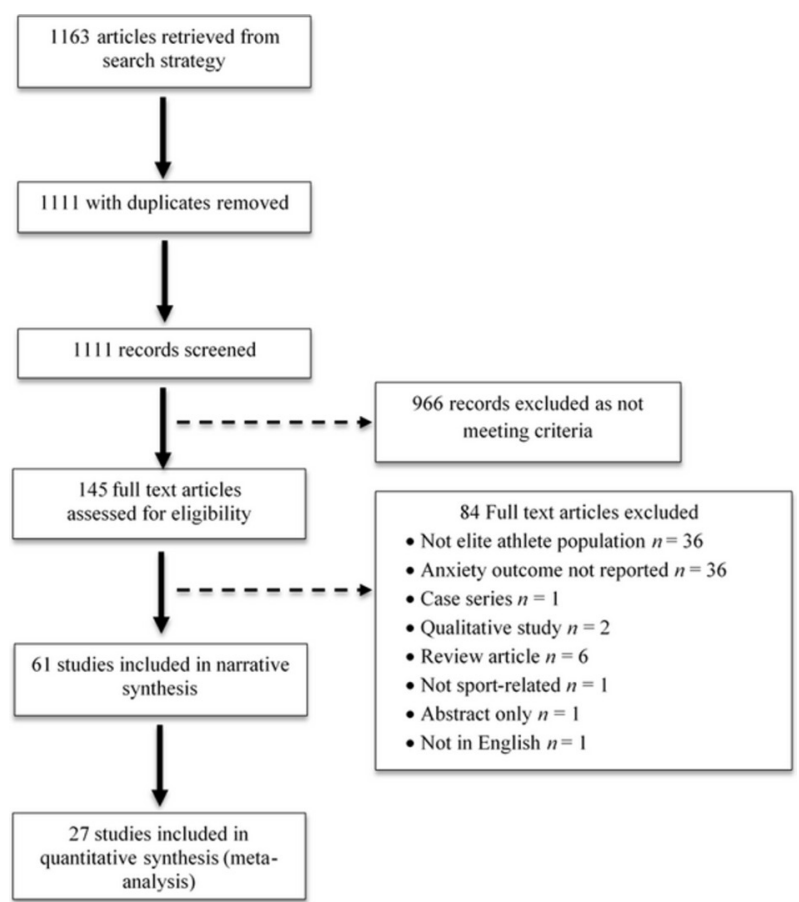

Figure 1 PRISMA study selection flow chart.

\section{Meta-analysis}

Of the 61 articles, 27 (44\%) were suitable for meta-analysis. After screening for determinants of anxiety, seven variables were identified: one population comparison (athletes vs non-athletes) and six determinant variables (gender, age, concussion, musculoskeletal injury, career dissatisfaction - typically measured as a dichotomous 'yes/no' variable, and recent adverse life events such as 'death of close friend' or 'change in financial state' within the past 6 months).

Five studies examined athletes compared with non-athletes. ${ }^{29-33}$ No differences in anxiety symptomology were observed between athletes and non-athletes $(d=-0.11, \mathrm{p}=0.28$; see figure 2$)$. Separate subgroup analysis of anxiety outcomes found no differences in generalised anxiety $(d=-0.04, \mathrm{p}=0.36)$ or trait anxiety scores $(d=0.07, \mathrm{p}=0.74)$. There was significant heterogeneity $(\mathrm{p}<0.01)$, which became non-significant after removal of two studies that had mixed sport samples $(Q=5.810, p=0.06 ; d=-0.06, p=0.798)$. There was no evidence of publication bias.

\section{Demographic determinants}

Ten articles measured anxiety by gender. ${ }^{3} 3133-40$ Overall, female athletes reported higher anxiety scores compared with male athletes $(d=0.38, \mathrm{p}<0.001)$. Moderate effect sizes were found across all anxiety measurement types (see figure 3 ). Homogeneity was upheld for the overall analysis and trait anxiety analyses, but not the general anxiety $(\mathrm{p}=0.047)$ or diagnosis analyses $(p=0.045)$. Homogeneity was achieved for general anxiety after removing the only single-sport sample $(Q=1.658, \mathrm{p}=0.437$; $d=0.28, \mathrm{p}<0.001),{ }^{33}$ though could not be reached for diagnosis as there were only two contributing studies. No publication bias was detected.

Three articles analysed anxiety by age. ${ }^{3641} 42$ Younger athletes ( $<25$ years) had higher anxiety levels compared with older athletes ( $>25$ years; $d=-0.34, p=0.003$; figure 4$)$. There were insufficient studies to perform subgroup analysis for anxiety outcomes. Heterogeneity and publication bias were not detected.
Table 1 Included articles grouped by anxiety measure

\begin{tabular}{|c|c|c|c|}
\hline Generalised anxiety & $\begin{array}{l}\text { State/trait } \\
\text { anxiety }\end{array}$ & $\begin{array}{l}\text { Global anxiety/ } \\
\text { depression }\end{array}$ & $\begin{array}{l}\text { Diagnosis (any } \\
\text { anxiety disorder) }\end{array}$ \\
\hline Brand et al $2013^{29}$ & $\begin{array}{l}\text { Bartholomew } \\
2003^{74}\end{array}$ & Brown et al $2017^{56}$ & Eissa et al $2018^{67}$ \\
\hline Byrd et al $2018^{43}$ & $\begin{array}{l}\text { Filaire et al } \\
1999^{30}\end{array}$ & $\begin{array}{l}\text { Foskett and } \\
\text { Longstaff } 2018^{41}\end{array}$ & Schaal et al $2011^{3}$ \\
\hline Çelebi et al $2015^{105}$ & $\begin{array}{l}\text { Gerber et al } \\
2011^{31}\end{array}$ & $\begin{array}{l}\text { Gouttebarge et al. } \\
2015 a^{52}\end{array}$ & Weber et al. $2018 c^{34}$ \\
\hline Drew et al $2017^{106}$ & $\begin{array}{l}\text { Gomez-Piqueras } \\
\text { et al } 2018^{107}\end{array}$ & $\begin{array}{l}\text { Gouttebarge et al. } \\
2015 b^{47}\end{array}$ & \\
\hline Du Preez et al $2016^{55}$ & $\begin{array}{l}\text { Gleeson et al } \\
1999^{108}\end{array}$ & $\begin{array}{l}\text { Gouttebarge et al. } \\
2016 a^{53}\end{array}$ & Tension/anxiety \\
\hline Fiorilli et al $2013^{32}$ & $\begin{array}{l}\text { Guillén and } \\
\text { Sánchez } 2009^{62}\end{array}$ & $\begin{array}{l}\text { Gouttebarge et al. } \\
2016 b^{109}\end{array}$ & Moore et al $2016^{69}$ \\
\hline Gross et al $2018^{94}$ & $\begin{array}{l}\text { Guo et al } \\
2018^{110}\end{array}$ & $\begin{array}{l}\text { Gouttebarge et al. } \\
2016 c^{54}\end{array}$ & Petito et al $2016^{70}$ \\
\hline Gulliver et al $2014^{35}$ & $\begin{array}{l}\text { Halvari and } \\
\text { Gjesme } 1995^{73}\end{array}$ & $\begin{array}{l}\text { Gouttebarge et al. } \\
2016 d^{48}\end{array}$ & Selmi et al $2018^{111}$ \\
\hline $\begin{array}{l}\text { Houltberg et al } \\
2018^{112}\end{array}$ & Han et al $2014^{65}$ & $\begin{array}{l}\text { Gouttebarge et al. } \\
2017 a^{44}\end{array}$ & \\
\hline $\begin{array}{l}\text { Junge and } \\
\text { Feddermann-Demont } \\
2016^{33}\end{array}$ & $\begin{array}{l}\text { Ivarsson et al } \\
2013^{36}\end{array}$ & $\begin{array}{l}\text { Gouttebarge et al. } \\
2017 b^{57}\end{array}$ & $\begin{array}{l}\text { Obsessive- } \\
\text { compulsive disorder }\end{array}$ \\
\hline $\begin{array}{l}\text { Junge and Prinz } \\
2018^{42}\end{array}$ & $\begin{array}{l}\text { Johnson and } \\
\text { Ivarsson } 2011^{49}\end{array}$ & $\begin{array}{l}\text { Gouttebarge et al. } \\
2017 c^{58}\end{array}$ & Cromer et al $2017^{63}$ \\
\hline Lancaster et al $2016^{37}$ & $\begin{array}{l}\text { Kang et al } \\
2016^{64}\end{array}$ & $\begin{array}{l}\text { Gouttebarge et al. } \\
2017 d^{50}\end{array}$ & \\
\hline Liu et al $2018^{113}$ & $\begin{array}{l}\text { Levit et al } \\
2018^{76}\end{array}$ & $\begin{array}{l}\text { Gouttebarge et al. } \\
2017 e^{51}\end{array}$ & \\
\hline Weber et al. $2018 a^{38}$ & $\begin{array}{l}\text { Millet et al } \\
2004^{95}\end{array}$ & $\begin{array}{l}\text { Gouttebarge et al } \\
2018^{59}\end{array}$ & \\
\hline Weber et al. $2018 b^{45}$ & $\begin{array}{l}\text { Morgan et al } \\
1988^{72}\end{array}$ & Kilic et al $2017^{114}$ & \\
\hline \multirow[t]{5}{*}{$\begin{array}{l}\text { Wilson and Madrigal } \\
2017^{71}\end{array}$} & $\begin{array}{l}\text { Sheehan et al. } \\
2018 a^{66}\end{array}$ & Kilic et al $2018^{12}$ & \\
\hline & $\begin{array}{l}\text { Sheehan et al. } \\
2018 b^{39}\end{array}$ & $\begin{array}{l}\text { Schuring et al } \\
2017^{60}\end{array}$ & \\
\hline & $\begin{array}{l}\text { Turner and } \\
\text { Raglin } 1996^{75}\end{array}$ & $\begin{array}{l}\text { Van Ramele et al } \\
2017^{115}\end{array}$ & \\
\hline & $\begin{array}{l}\text { Yang et al } \\
2007^{40}\end{array}$ & & \\
\hline & $\begin{array}{l}\text { Yang et al } \\
2015^{46}\end{array}$ & & \\
\hline
\end{tabular}

Concussion and musculoskeletal injury

Four articles examined anxiety by concussion frequency and symptomology. ${ }^{43-46}$ Figure 5 denotes a non-significant effect of concussion $(d=0.33, \mathrm{p}=0.053)$. There was significant heterogeneity that became non-significant after visual inspection advocated removal of an outlier study. ${ }^{43}$ The removal of the study also led to a small significant effect $(d=0.17, \mathrm{p}=0.023)$, where athletes with concussion history showed higher anxiety symptoms. There was no evidence of publication bias in the initial analysis, though there was evidence after the outlier study was removed. Accordingly, these results should be interpreted cautiously.

Nine studies measured anxiety by musculoskeletal injury prevalence. ${ }^{33} 35404147-51$ An overall significant small-moderate effect indicated injured athletes reported higher levels of anxiety $(d=0.31$, $\mathrm{p}<0.001)$. Subgroup analyses indicated significant effects across all anxiety outcomes (see figure 6). Homogeneity was upheld across all analyses. There was evidence of publication bias, marginally adjusting the estimated effect size $(d=0.29)$. 


\begin{tabular}{|c|c|c|c|}
\hline Types of athletes & & Sample characteristics & \\
\hline National level ${ }^{*}$ & $17(27.8 \%)$ & Mean sample size (n) & 444 \\
\hline Collegiate/university & $15(24.6 \%)$ & Median sample size (n) & 217 \\
\hline Professional & $15(24.6 \%)$ & Mean age of sample (years) & 24.5 \\
\hline Mixed levels & $7(11.5 \%)$ & $\begin{array}{l}\text { Median age of sample } \\
\text { (years) }\end{array}$ & 23.9 \\
\hline Professional youth & $4(6.6 \%)$ & $\begin{array}{l}\text { Mean retirement length } \\
\text { (years) }\end{array}$ & 5.9 \\
\hline Olympic & $3(4.9 \%)$ & Aggregate sample size & 27515 \\
\hline Types of sports & & Aggregate male athletes & $16547(60 \%)$ \\
\hline Multiple & $29(48 \%)$ & Aggregate female athletes & 7964 (28.9\%) \\
\hline Soccer & $13(21 \%)$ & Study design & \\
\hline Rugby & $5(8 \%)$ & Cross-sectional & $36(59 \%)$ \\
\hline Basketball & $3(5 \%)$ & Cohort & $17(28 \%)$ \\
\hline Track and field & $3(5 \%)$ & Longitudinal & $2(3 \%)$ \\
\hline Gaelic sports (eg, hurling) & $2(3 \%)$ & Experimental & $2(3 \%)$ \\
\hline American football & $1(2 \%)$ & Quasi-experimental & $2(3 \%)$ \\
\hline Baseball & $1(2 \%)$ & Randomised clinical trial & $1(2 \%)$ \\
\hline Golf & $1(2 \%)$ & Mixed design & $1(2 \%)$ \\
\hline Ice hockey & $1(2 \%)$ & & \\
\hline Swimming & $1(2 \%)$ & & \\
\hline
\end{tabular}

\section{Career dissatisfaction and recent adverse life events}

Six articles analysed anxiety by career dissatisfaction. ${ }^{41} 48$ 50-53 Athletes with higher ratings of career dissatisfaction reported higher global anxiety/depression scores compared with career-satisfied athletes $(d=0.45, \mathrm{p}<0.01$; figure 7$)$. Heterogeneity was observed, though became non-significant after the removal of the only study with a retired athlete sample $(Q=6.348, \mathrm{p}=0.175$; $d=0.55, \mathrm{p}<0.001) .{ }^{53}$ Publication bias was detected, slightly reducing the estimated effect size $(d=0.45)$.

Five studies examined anxiety by recent adverse life events. ${ }^{50-54}$ Figure 8 shows a small effect of recent adverse life events on global anxiety/depression, where higher anxiety scores were found in athletes who had experienced one or more recent adverse life events $(d=0.26, \mathrm{p}<0.001)$. There was no evidence of heterogeneity or publication bias. Exploratory subgroup analysis of current versus former athletes found a small effect for former athletes $(d=0.26, \mathrm{p}<0.001, k=2),{ }^{53}{ }^{54}$ but not current athletes $(d=0.23$, $\mathrm{p}=0.113, k=3) .{ }^{50-52}$

\section{Narrative results}

Online supplementary table 3 summarises key findings of each of the 61 articles. The following sections summarise other results not included in the meta-analysis.

\section{Comorbidities}

Diagnosed comorbidity was found for GAD occurring with depression, ${ }^{42}$ and for multiple anxiety disorders occurring together, for example GAD occurring with OCD, with agoraphobia or with panic disorder. ${ }^{3}$ For symptomatology, higher anxiety scores were commonly associated with higher depressive symptoms. ${ }^{4046}$ Self-reported history of mental health disorders was also associated with higher self-reported generalised anxiety symptoms in rugby players during a competitive season and training season. ${ }^{55}$ Comorbidity of common mental health symptoms (including global anxiety/ depression) was examined across multiple studies; however, due to non-specific reporting, it cannot be determined if indicated comorbidity encompassed anxiety symptoms. ${ }^{12} 4448505156-61$

\section{Competitive level and experience}

Elite athletes playing at higher competitive levels typically reported fewer symptoms of anxiety than athletes in lower competitive ranks, ${ }^{42} 6263$ for instance, first-league compared with secondleague soccer and basketball players. ${ }^{42} 62$ Similarly, basketball and soccer players with more years of playing experience exhibited lower anxiety scores than athletes with less experience. ${ }^{42} 62$ Lastly, trait anxiety scores were lower in high-ranked compared with low-ranked professional golfers, ${ }^{64}$ although not in high-ranked and low-ranked baseball players. ${ }^{65}$

\section{Motivation and coping}

Two studies measuring team-sport athletes (eg, football, hurling) reported a negative correlation between trait anxiety and several measures of motivation, including autonomy, integrated regulation (behaviours congruent with one's value system) and intrinsic motivation (actions that produce satisfaction from participation). ${ }^{39} 66$ Trait anxiety was also positively correlated with non-regulated motivation (lack of intention to perform an action). ${ }^{66}$ Combined team and individual sport athletes with panic disorder were less likely to use social support coping, positive reinterpretation (reappraising an adverse situation in an optimistic way) and information seeking compared with athletes without that diagnosis. ${ }^{67}$ Athletes with GAD also reported low social support coping and information seeking, while athletes with specific phobias indicated high self-blame, helplessness and emotion-focused coping (eg, regulating distress with relaxation techniques). ${ }^{67}$

\section{Neurological and biological factors}

Tension/anxiety, exemplified by uneasiness and nervousness, ${ }^{68}$ was negatively correlated with frontal alpha-asymmetries detected on electroencephalography (EEG) in soccer and American football players with concussion history who had returned to play. ${ }^{69}$

\begin{tabular}{|c|c|c|c|c|c|c|}
\hline \multirow[t]{2}{*}{ Study name } & \multirow[t]{2}{*}{ Sample $\mathrm{n}$} & \multicolumn{4}{|c|}{ Statistics for each study } & \multirow{2}{*}{$\begin{array}{c}\text { Std diff in means } \\
\text { and } 95 \% \mathrm{Cl}\end{array}$} \\
\hline & & $\begin{array}{l}\text { Std diff } \\
\text { in means }\end{array}$ & $\begin{array}{l}\text { Lower } \\
\text { limit }\end{array}$ & $\begin{array}{l}\text { Upper } \\
\text { limit }\end{array}$ & p-Value & \\
\hline Fiorili et al. 2013 & 46 & -0.305 & -0.886 & 0.277 & 0.305 & - \\
\hline Junge and Feddermenn-Dermont 2016 & 5480 & -0.242 & -0.339 & -0.146 & 0.000 & \\
\hline Gerber et al. 2011 & 434 & -0.233 & -0.422 & -0.043 & 0.016 & \\
\hline Brand et al. 2012 & 1298 & 0.053 & -0.100 & 0.205 & 0.499 & \\
\hline \multirow[t]{2}{*}{ Flaire et al. 1999} & 20 & 0.663 & -0.071 & 1.397 & 0.077 & \\
\hline & & -0.108 & -0.304 & 0.087 & 0.278 & \\
\hline
\end{tabular}

Heterogeneity: $Q=15.885, d f=4, p=0.003, I^{2}=74.818$

Figure 2 Forest plot for anxiety in athletes and non-athletes. 


\begin{tabular}{|c|c|c|c|c|c|c|c|c|}
\hline \multirow{3}{*}{$\begin{array}{l}\text { Study name } \\
\text { Schaal et al. } 2011\end{array}$} & \multirow{3}{*}{$\begin{array}{l}\frac{\text { Group by }}{\text { Anxiety Outcome }} \\
\text { Diagnosis }\end{array}$} & \multirow{3}{*}{$\begin{array}{l}\text { Sample n } \\
2067\end{array}$} & \multicolumn{4}{|c|}{ Statistics for each study } & \multirow{2}{*}{\multicolumn{2}{|c|}{$\begin{array}{l}\text { Std diff in means } \\
\text { and } 95 \% \mathrm{Cl}\end{array}$}} \\
\hline & & & \multicolumn{4}{|c|}{$\begin{array}{l}\text { Std diff Lower Upper } \\
\text { n means limit limit p-Value }\end{array}$} & & \\
\hline & & & 0.280 & 0.109 & 0.451 & 0.001 & & \\
\hline \multirow{2}{*}{ Weber et al. $2018 \mathrm{c}$} & Diagnosis & 2652 & 0.648 & 0.331 & 0.965 & 0.000 & & \\
\hline & Diagnosis & & 0.439 & 0.082 & 0.796 & 0.016 & & \\
\hline Weber et al. 2018a & General Anxiety & 326 & 0.167 & -0.051 & 0.385 & 0.133 & & \\
\hline Lancæster et al. 2016 & General Anxiety & 1991 & 0.301 & 0.153 & 0.450 & 0.000 & & \\
\hline Gulliver et al. 2014 & General Anxiety & 224 & 0.379 & 0.115 & 0.644 & 0.005 & & \\
\hline \multirow[t]{2}{*}{ Junge and Fedderman-Demont 2016} & General Anxiety & 471 & 0.580 & 0.374 & 0.787 & 0.000 & & \\
\hline & General Arxiety & & 0.355 & 0.188 & 0.521 & 0.000 & & \\
\hline Sheehan \& al. 2018b & Trait & 38 & 0.261 & -0.378 & 0.901 & 0.423 & & \\
\hline Yang et al. 2007 & Trait & 257 & 0.379 & 0.012 & 0.745 & 0.043 & & \\
\hline Gerber et al. 2011 & Trait & 434 & 0.392 & 0.194 & 0.590 & 0.000 & & \\
\hline \multirow{3}{*}{ N varsson et al. 2013} & Trait & 56 & 0.864 & 0.281 & 1.447 & 0.004 & & \\
\hline & Trait & & 0.417 & 0.256 & 0.579 & 0.000 & & \\
\hline & \multicolumn{8}{|c|}{$\begin{array}{ccc}-1.00 & -0.50 & 0.00\end{array}$} \\
\hline \multicolumn{9}{|c|}{$\begin{array}{l}\text { Heterogeneity: } \\
\text { Overall Anxiety: } Q=14.124, d f=9, p=0.118, I^{2}=36.279 ; \text { Diagnosis: } Q=4.003, d f=1, p=0.045, I^{2}=75.017 ; \text { Male } \\
\text { General Anxiety: } Q=7.951, d f=3, p=0.047, I^{2}=62.271 \text {; Trait: } Q=2.585, d f=3, p=0.460, I^{2}=0.000\end{array}$} \\
\hline
\end{tabular}

Figure 3 Subgroup analyses for anxiety outcomes in male and female athletes.

Tension/anxiety was also higher in team-sport athletes with an 1/1 genotype compared with an s/s genotype for the 5-HTTLPR serotonin transporter. ${ }^{70}$ Symptoms of generalised anxiety were negatively correlated with several markers of omega-3 polyunsaturated fatty acids, including blood levels of eicosapentaenoic acid, docosapentaenoic acid and HS-omega-3 indices, in athletes across a range of sports (basketball, soccer, rifle, and golf). ${ }^{71}$

\section{Performance}

Trait anxiety was negatively associated with performance in two studies, one regarding race times for long-distance runners ${ }^{72}$ and the other regarding performance errors following a competitive motor task in collegiate athletes. ${ }^{73}$ For state anxiety, accurate performance feedback from an experimenter was associated with lower anxiety shortly after a competitive task, whereas low feedback was associated with a short-term increase in state anxiety for rowing and cross-country athletes. ${ }^{74}$ Similarly, 'optimal' state anxiety (dependent on an athlete's recollection) was associated with high performance in track and field athletes. ${ }^{75}$

\section{Sport type}

Comparisons across sport types were rarely reported in the included literature. One study found that aesthetic sport athletes (eg, gymnastics, figure skating) had the highest rates of GAD, while risk sports (eg, aerial sports, motor sports) had the lowest rates in both male and female athletes. ${ }^{3}$ One study found handball players had higher state and trait anxiety compared with volleyball players. ${ }^{30}$ Lastly, no differences in state and trait anxiety were found between team-sport and individual-sport athletes. ${ }^{76}$

\section{Quality appraisal (risk of bias)}

For full quality appraisal, see online supplementary files 4-9e. The overall appraisal score (as a proportion) for all studies was 0.8 . Articles were typically of high quality, with 41 articles (67\%) scoring 0.8 and above. Nineteen articles $(31 \%)$ were of moderate methodological quality $(0.5-0.79)$, and one article $(2 \%)$ was of poor methodological quality $(<0.5)$. No studies were excluded based on these analyses.

\section{DISCUSSION}

The present study sought to identify determinants of anxiety symptoms and disorders among elite athletes, in addition to summarising the extant literature on this population to date. As noted by others, ${ }^{77}$ findings of this review highlight a rapid increase in this research domain, with $75 \%(n=46)$ of included studies published within the last 5 years. The meta-analysis

\begin{tabular}{|c|c|c|c|c|c|c|}
\hline \multirow[t]{2}{*}{ Study name } & \multirow[t]{2}{*}{ Sample n } & \multicolumn{4}{|c|}{ Statistics for each study } & \multirow{2}{*}{$\begin{array}{l}\text { Std diff in means } \\
\text { and } 95 \% \mathrm{Cl}\end{array}$} \\
\hline & & $\begin{array}{l}\text { Std diff } \\
\text { in means }\end{array}$ & $\begin{array}{l}\text { Lower } \\
\text { limit }\end{array}$ & $\begin{array}{l}\text { Upper } \\
\text { limit }\end{array}$ & $p-V$ alue & \\
\hline Junge and Prine 2018 & 284 & -0.432 & -0.765 & -0.099 & 0.011 & \\
\hline Ivarsson et al. 2013 & 108 & -0.392 & -0.933 & 0.150 & 0.156 & \\
\hline \multirow[t]{4}{*}{ Foskett and Longstaff 2018} & 136 & -0.197 & -0.581 & 0.187 & 0.314 & \\
\hline & & -0.342 & -0.570 & -0.114 & 0.003 & \\
\hline & & & & & & $\begin{array}{lllll}-1.00 & -0.50 & 0.00 & 0.50 & 1.00\end{array}$ \\
\hline & & & & & & Younger $(<25)$ \\
\hline
\end{tabular}

Figure 4 Forest plot for anxiety among athletes older and younger than 25 years. 


\begin{tabular}{|c|c|c|c|c|c|c|}
\hline \multirow[t]{2}{*}{ Study name } & \multirow[t]{2}{*}{ Sample $\mathrm{n}$} & \multicolumn{4}{|c|}{ Statistics for each study } & \multirow{2}{*}{$\begin{array}{l}\text { Std diff in means } \\
\text { and } 95 \% \mathrm{Cl}\end{array}$} \\
\hline & & $\begin{array}{l}\text { Std diff } \\
\text { in means }\end{array}$ & $\begin{array}{l}\text { Lower } \\
\text { limit }\end{array}$ & $\begin{array}{l}\text { Upper } \\
\text { limit }\end{array}$ & p-Value & \\
\hline Gouttebarge et al. 2017a & 576 & 0.107 & -0.085 & 0.298 & 0.275 & \\
\hline Yang et al. 2015 & 71 & 0.242 & -0.321 & 0.804 & 0.400 & \\
\hline Weber et al. $2018 b$ & 244 & 0.268 & 0.016 & 0.521 & 0.037 & \\
\hline \multirow[t]{4}{*}{ Byrd et al. 2018} & 30 & 1.670 & 0.687 & 2653 & 0.001 & \\
\hline & & 0.330 & -0.004 & 0.665 & 0.053 & \\
\hline & & & & & & $-2.00-1.000 .001 .002 .00$ \\
\hline & & & & & & No concussion Concussion \\
\hline Heterogeneity: $Q=9.804$, & $=3, p=0.020$, & $=69.401$ & & & & \\
\hline
\end{tabular}

Figure 5 Forest plot for anxiety in athletes with and without concussion history.

outcomes indicated several general factors as being salient to symptomatic anxiety in elite athletes, including female gender, younger age and recent experience of adverse life events. These factors are consistent with findings from a recent meta-analysis for competitive anxiety in athletes, ${ }^{14}$ and trends in the general population. ${ }^{1478} 79$ Meta-analysis also indicated the role of two athlete-specific factors, namely current musculoskeletal injury and sporting career dissatisfaction, as being associated with anxiety symptoms. This is the first meta-analysis to highlight these domains as potential risk factors for symptomatic anxiety among elite athletes.

Considering the athlete-specific factors, musculoskeletal injury and career dissatisfaction can be understood as prominently biopsychosocial influencers of mental health. ${ }^{80}$ Attention to these factors, when present for elite athletes, may assist sports medicine practitioners in planning for the psychological management needs of athlete cohorts. While individual intervention may be required for affected athletes (eg, psychotherapy, pharmacotherapy), sport administrators and officials may also wish to consider the broader environmental factors that may contribute to athlete injury or career dissatisfaction. For example, systemic approaches may involve challenging once normative attitudes about the need for athletes to play or train though pain or injury in order to demonstrate resilience or 'toughness' ${ }^{81}$

Additionally, retirement status as an athlete-specific subgroup analysis indicated that experiencing recent adverse life events was associated with higher global anxiety/depression in former but not current athletes. Established support services for athletes that have transitioned out of elite sport should consider the presence and impact of recent adverse life events in this population as a potential risk factor of symptomatic anxiety.

Meta-analysis of the five studies that also reported data from a non-athlete control group ${ }^{29-33}$ indicated that athletes report anxiety symptoms at comparable severity with the general population. Similarly, a recent meta-analysis identified that high-performance athletes were no more likely than non-athletes to report mild to severe symptoms of depression. ${ }^{82}$ This is consistent with assertions that elite athletes are not necessarily protected from mental health symptoms by virtue of their sporting role, ${ }^{83}$ strengthening the rationale for an increased focus on the mental health of this population, and the broader development of the field of sports mental health. ${ }^{84} 85$ Anxiety disorders (especially GAD and social anxiety) are relatively prevalent in the general population, and may be similarly so in elite athletes, although research into diagnosed disorders (relative to symptoms) in this population is lacking.

This study also examined a range of broader outcomes that were not suitable for inclusion in the meta-analysis. Unsurprisingly, it was found that anxiety symptoms in elite athletes were associated with symptoms of depression, ${ }^{40} 46$ or a depression diagnosis, ${ }^{42}$ in addition to other concurrent anxiety disorder diagnoses. ${ }^{3}$ Anxiety symptoms were lower among more experienced

\begin{tabular}{|c|c|c|c|c|c|c|c|c|c|c|}
\hline \multirow[t]{2}{*}{ Studyname } & \multirow{2}{*}{$\frac{\text { Group by }}{\text { Anxiety Outcome }}$} & \multirow[t]{2}{*}{ Samplen } & \multicolumn{4}{|c|}{ Statistics for each study } & \multirow{2}{*}{\multicolumn{4}{|c|}{$\begin{array}{l}\text { Std diff in means } \\
\text { and } 95 \% \mathrm{Cl}\end{array}$}} \\
\hline & & & $\begin{array}{l}\text { Std diff } \\
\text { in means }\end{array}$ & $\begin{array}{c}\text { Lower } \\
\text { limit }\end{array}$ & $\begin{array}{l}\text { Upper } \\
\text { limit }\end{array}$ & p-Value & & & & \\
\hline Junge and Feddermann-Demont 2016 & General Ansety & 446 & 0.301 & 0.056 & 0.546 & 0016 & & & & \\
\hline \multirow[t]{2}{*}{ Guliner et al. 2014} & General Anxiety & 224 & 0.353 & 0.045 & 0.661 & 0005 & & & & \\
\hline & General Anxiety & & 0.321 & 0.130 & 0.513 & 0001 & & & & \\
\hline Gouteberge of al. 2017e & Globel Avow Dep & 135 & 0.012 & -0.482 & 0.506 & 0963 & & & & \\
\hline Gouteberge et al. $2015 \mathrm{~b}$ & Globel AvowDep & 253 & 0.259 & -0.015 & 0.533 & 0064 & & & & \\
\hline Goutebarge et al. 2017d & Globel Arowep & 203 & 0.353 & 0.073 & 0.632 & 0.013 & & & & \\
\hline Foslett and Longstaff 2018 & Globel AvwDep & 137 & 0.539 & 0.061 & 1.018 & 00027 & & & & \\
\hline \multirow[t]{2}{*}{ Gouttebarge et al. 2016d } & Globel AvowDep & 204 & 0.624 & 0.094 & 1.154 & 0021 & & & & \\
\hline & Globel AvorDep & & 0.330 & 0.168 & 0.492 & 0000 & & & & \\
\hline Yang et al. 2007 & Trait & 257 & 0.209 & -0.036 & 0.455 & 0095 & & & & \\
\hline \multirow[t]{3}{*}{ Johrson and Marsson 2011} & Trat & 108 & 0.440 & 0.048 & 0832 & 00028 & & & & \\
\hline & Trait & & 0.274 & 0.006 & 0.483 & 0010 & & & & \\
\hline & & & & & & & -1.00 & -0.50 & $0.00 \quad 0.50$ & 1.00 \\
\hline $\begin{array}{l}\text { Heterogeneity: } \\
\text { Overall: } Q=4.995, d f=8, p=0.7 \\
d f=4, p=0.435, l^{2}=0.000 ; \text { Trait: }\end{array}$ & $\begin{array}{l}=0.000 ; \text { Gener } \\
0.955, d f=1, p\end{array}$ & $6, d f=$ & $7,1^{2}=$ & $0 ; \mathbf{G l}$ & $x / 2$ & $=3.7$ & & ninjured & ured & \\
\hline
\end{tabular}

Figure 6 Subgroup analyses for anxiety outcomes in injured and uninjured athletes. 


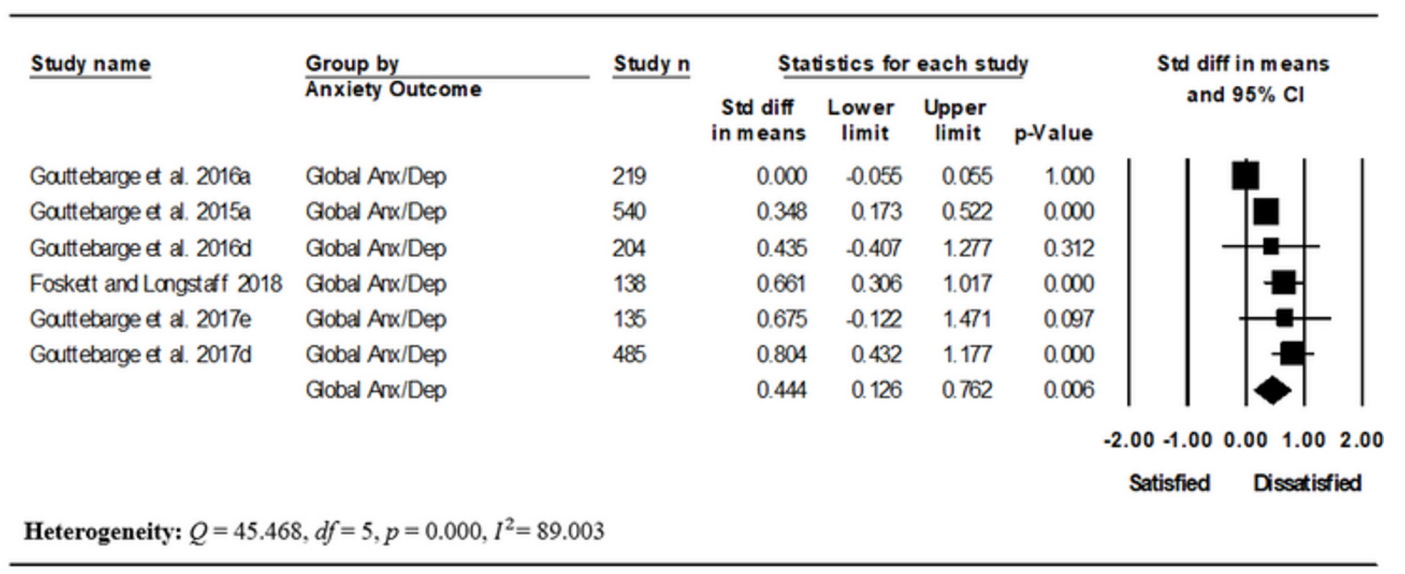

Figure 7 Forest plot for anxiety in athletes with and without career dissatisfaction.

athletes, ${ }^{42} 6263$ and may have a negative relationship with both motivation $^{3966}$ and discrete aspects of sporting performance. ${ }^{72} 73$ These findings further support the role of preventative or early intervention approaches in the management of anxiety disorders in elite athletes, as this may lower the likelihood of developing comorbid mental health problems (such as depression), and increase the likelihood of motivation and performance remaining intact. Psychological factors considered essential for elite athletes successful at the highest levels include affect and self-regulation, maintaining motivation, self-confidence and adaptive coping strategies, alongside supportive interpersonal relationships. ${ }^{86}$ Development of and attention to such factors will almost certainly assist athletes in managing anxiety (either at the symptom or diagnostic level), and coupled with evidencebased intervention (eg, cognitive behavioural therapy), should be considered by sports medicine practitioners and sports officials in supporting the mental health of athlete populations.

The overall mean age for participants in the included studies was 24.5 years, which is inclusive of several studies that incorporated recently retired athletes. For most Olympic and professional sports, the years of competitive elite competition directly overlap with the peak ages of onset for mental disorders, with $75 \%$ of all mental disorders shown to emerge prior to age $25{ }^{87}$ As anxiety disorders account for a large proportion of the burden of disease among all mental health problems, ${ }^{88}$ their presence among and impacts on elite athlete populations affords greater attention and action where needed. Younger populations are also known to experience particular barriers to accessing mental healthcare, ${ }^{89}$ and elite athletes have additional role-related barriers including concerns about stigma and the impact of disclosure and help-seeking on team selection. ${ }^{90}$ The development of youth-specific models of mental healthcare for those under 25 years has resulted in decreased stigma and service barriers, improving access to evidence-based intervention. ${ }^{91}$ Athlete-specific models of care are emerging, ${ }^{92}$ and efforts to consolidate and expand such initiatives warrant the support of governing bodies, codes, and competitions.

\section{Limitations and future directions}

We acknowledge several limitations. In general, the quality of study reporting was relatively high, suggesting an overall low risk of bias in the included studies. Nonetheless, a wide range of anxiety symptom rating scales were employed in the studies included in the meta-analysis. Where possible, we conducted subgroup analyses for measures differentiating trait, generalised, global and diagnosed anxiety. Heterogeneity was initially observed for the gender, concussion and career dissatisfaction analyses, though resolved after inspection of sample-specific differences (eg, differences between sports). Additionally, only a small proportion of the included studies reported a confirmed clinician-rated or interviewer-rated diagnosis of anxiety, with most studies employing self-reported symptoms. Distinguishing anxiety symptoms from diagnostic disorders is important given functional impairment and associated distress is likely to be more severe in the latter. Studies examining outcomes of athletes within the clinical range for anxiety disorders are currently lacking, and as the field progresses, future reviews should look

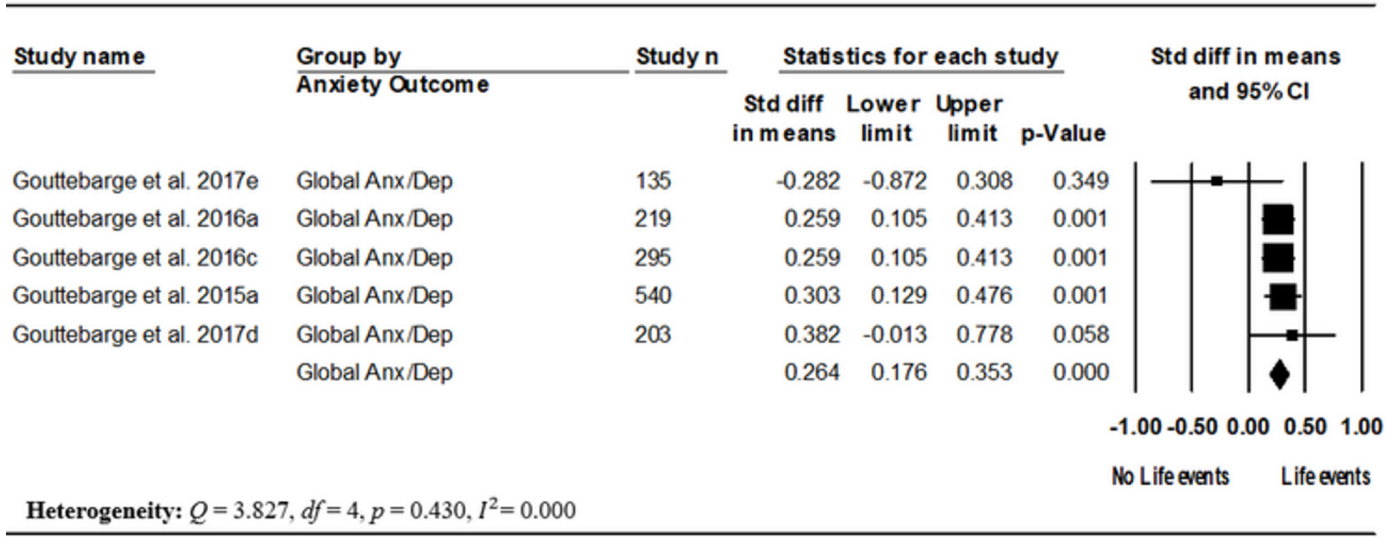

Figure 8 Forest plot for anxiety in athletes with and without adverse life events within six months. 
to examine potential group differences according to clinician or interviewer-rated diagnoses of anxiety versus self-report symptoms, given there may be bias in self-report measures, either in terms of under-reporting or over-reporting. ${ }^{93}$ Further, attention should be given to patterns of symptom onset, duration, severity and associated distress ${ }^{4}$ in order to distinguish anxiety disorders from competition-based performance anxiety.

While a relatively large number of studies were included in this review, only one study reported on the effects of an intervention, and there were only a handful of studies using a longitudinal design. The single included intervention study was a small RCT testing a mindfulness-acceptance-based approach. ${ }^{94}$ While other groups have developed athlete-specific mental health interventions (eg, the athlete optimisation approach for college athletes of Donohue et al), ${ }^{92}$ anxiety outcomes of these interventions are yet to be explored. The present results highlight the urgent need for well-conducted intervention-based RCTs, and specific attention towards the acceptability and efficacy of psychotherapy approaches among elite athletes is needed. Similarly, longitudinal studies in elite athlete populations are needed to shed light on anxiety symptom patterns according to temporal factors. Related to this, the present study was unable to conclude whether time in competitive season impacted outcomes. It is possible that a seasonal effect of athlete anxiety may exist in line with peak training loads, recovery and proximity to major competition. $^{95}$

The present review discovered markedly higher symptomatic anxiety among female athletes than their male counterparts. Emerging research suggests that younger males, who can be socialised to deny or suppress perceived vulnerabilities in sport settings, ${ }^{96}$ may exhibit mental health symptoms through a constellation of behaviours beyond those included in diagnostic criteria for internalising disorders such as anxiety. ${ }^{97} 98$ Research attention to anxiety symptoms (which are known to be higher in females), in the context of broader comorbidity domains of risk-taking, problematic anger or aggression, and substance misuse (which are known to be higher in males), ${ }^{99} 100$ may be an important step in recognising athletes at risk of mental health symptoms or disorders who may otherwise go unidentified via existing anxiety rating scales or diagnostic criteria.

Further, the present study identified an under-representation of female athletes and para-athletes. The ratio of males to females was roughly double, and only one article reported data for para-athletes. ${ }^{32}$ Future research should aim to explore these samples. Additionally, some factors pertinent to mental health are yet to be examined, including athlete sexuality and ethnicity. Future studies should consider these factors given consistent findings that minority sexuality and ethnicity differently impact mental health. ${ }^{101} 102$

To date, studies are yet to conclusively determine cross-sport comparisons for anxiety disorders in elite athletes. The main exceptions to this are work by Schaal and colleagues, ${ }^{3}$ who found higher rates of GAD among elite athletes competing in aesthetic sports, and work by Levit and colleagues, ${ }^{76}$ who found no differences in anxiety symptoms between team-based and individual athletes. Comparatively, growing literature of depression in elite athletes suggests that individual-sport athletes exhibit higher depressive symptoms than team-sport athletes. ${ }^{3}{ }^{103}$ Future comparisons are needed, particularly taking account of the relative contribution of general versus athlete-specific factors in this regard. Future studies using meta-regression techniques may help quantify the unique contribution of athlete-specific factors.

Any link between the presence of an anxiety disorder or anxiety symptoms and competitive performance impacts is not yet well understood. As an extension, it is unclear whether athlete-specific interventions that provide remission of anxiety symptoms may be associated with changes in performance. Furthermore, while GAD and generalised anxiety symptoms were well addressed in this review, at present we know far less about other anxiety disorders (eg, OCD, panic disorder, social phobia) and a related personality disorder (ie, obsessive-compulsive personality disorder; OCPD) in elite athletes. Ritualistic behaviours or routines are common among elite athletes, ${ }^{86}$ and potential overlap between such behaviours and anxiety disorders, especially OCD and OCPD, remains poorly understood.

Finally, additional research is needed on neurological or biological aspects of anxiety in elite athletes. There was a relative lack of attention to this among included studies, and such research could consider EEG profiles, ${ }^{69}$ or imaging approaches, the effects of biotherapeutic agents such as omega- 3 polyunsaturated fatty acids ${ }^{71}$ or cannabidiol, which is currently not a prohibited substance for athletes, ${ }^{104}$ and genomics and related hereditary analytic approaches. ${ }^{104}$

\section{Conclusions}

Factors associated with anxiety symptoms among elite athletes provide useful information for preventative intervention or acute phase management. While there are research gaps related to particular subtypes of anxiety in elite populations (eg, OCD, panic disorder), this review highlights both general factors and athlete-specific factors associated with symptom burden. Though data are lacking, it seems feasible that focused and acceptable interventions for anxiety symptoms among athlete populations may enhance career longevity and improve role satisfaction. Youth-specific models of mental healthcare that have been established internationally are likely to be useful for those aiming to develop innovative athlete-specific services. While it remains to be seen whether such approaches will improve sporting or athletic performance, the next decade is certain to see major investment into the mental health of athletes and expansion of sports mental health as a discipline.

\section{Author affiliations}

${ }^{1}$ Research and Translation, Orygen, The National Centre of Excellence in Youth Mental Health, Melbourne, Victoria, Australia

${ }^{2}$ Centre for Youth Mental Health, University of Melbourne, Melbourne, Victoria, Australia

${ }^{3}$ Department of Psychiatry, Hotchkiss Brain Institute, University of Calgary, Calgary, Alberta, Canada

${ }^{4}$ Center for Health and Sport, Western University of Health Sciences, Pomona, California, USA

${ }^{5}$ Department of Sport and Exercise Science, University of Portsmouth, Portsmouth, UK ${ }^{6}$ Department of Orthopaedic Surgery, Amsterdam Movement Sciences, Amsterdam UMC, University of Amsterdam, Meibergdreef, The Netherlands

${ }^{7}$ AMC/NUmc IOC Research Center of Excellence, Amsterdam Collaboration on Health and Safety in Sports (ACHSS), Amsterdam, The Netherlands

${ }^{8}$ Department of Psychiatry, University of Wisconsin School of Medicine and Public Health, Madison, Wisconsin, USA

${ }^{9}$ University Health Services, University of Wisconsin, Madison, Wisconsin, USA

${ }^{10}$ Ebling Library for the Health Sciences, University of Wisconsin-Madison, Madison, Wisconsin, USA

${ }^{11}$ National Collegiate Athletic Association (NCAA), Indianapolis, Indiana, USA

Acknowledgements The authors thank the other participants in the 2018 International Olympic Committee Consensus Meeting on Mental Health in Elite Athletes, including Cindy Miller Aron, Antonia Baum, Abhinav Bindra, Richard Budgett, Niccolo Campriani, Joao Mauricio Castaldelli-Maia, Alan Currie, Jeff Derevensky, Lars Engebretsen, Ira Glick, Michael Grandner, Doug Hyun Han, David McDuff, Margo Mountjoy, Aslihan Polat, Margot Putukian, Allen Sills, Torbjorn Soligard, Todd Stull, Leslie Swartz and Li Jing Zhu, for their input on the development and interpretation of this research.

Contributors All authors conceived the study. MEH conducted the search, and SMR, RP and KG screened the articles. KG abstracted the data and performed the 
statistical analysis. SMR and OS-E reviewed the data for consistency. SMR and KG drafted the manuscript. All authors critically reviewed the manuscript and approved the final version.

Funding The authors have not declared a specific grant for this research from any funding agency in the public, commercial or not-for-profit sectors.

Competing interests None declared.

Patient consent for publication Not required.

Provenance and peer review Not commissioned; externally peer reviewed.

Open access This is an open access article distributed in accordance with the Creative Commons Attribution Non Commercial (CC BY-NC 4.0) license, which permits others to distribute, remix, adapt, build upon this work non-commercially, and license their derivative works on different terms, provided the original work is properly cited, appropriate credit is given, any changes made indicated, and the use is non-commercial. See: http://creativecommons.org/licenses/by-nc/4.0/

\section{REFERENCES}

1 Somers JM, Goldner EM, Waraich P, et al. Prevalence and incidence studies of anxiety disorders: a systematic review of the literature. Can J Psychiatry 2006;51:100-13.

2 Wittchen $\mathrm{H}-\mathrm{U}$, Jacobi F. Size and burden of mental disorders in Europe-a critical review and appraisal of 27 studies. Eur Neuropsychopharmacol 2005:15:357-76.

3 Schaal K, Tafflet M, Nassif H, et al. Psychological balance in high level athletes: gender-based differences and sport-specific patterns. PLoS One 2011;6:e19007.

4 American Psychiatric Association. Diagnostic and statistical manual of mental disorders (DSM-5®). Washington: American Psychiatric Pub, 2013.

5 Pacheco-Unguetti AP, Acosta A, Callejas A, et al. Attention and anxiety: different attentional functioning under state and trait anxiety. Psychol Sci 2010;21:298-304

6 Spielberger CD, Reheiser EC. Measuring anxiety, anger, depression, and curiosity as emotional states and personality traits with the STAI, STAXI, and STPI. Comprehensive Handbook of psychological assessment 2004;2:70-86.

7 Hodge K, Smith W. Public expectation, pressure, and avoiding the choke: a case study from elite sport. Sport Psychol 2014;28:375-89.

8 Brown CJ, Webb TL, Robinson MA, et al. Athletes' retirement from elite sport: A qualitative study of parents and partners' experiences. Psycho/ Sport Exerc 2019;40:51-60.

9 Gustafsson $H$, Hassmén P, Kenttä $\mathrm{G}$, et al. A qualitative analysis of burnout in elite Swedish athletes. Psychol Sport Exerc 2008;9:800-16.

10 Lavallée L, Flint F. The relationship of stress, competitive anxiety, mood state, and social support to athletic injury. J Ath/ Train 1996;31.

11 Ivarsson A, Johnson U. Psychological factors as predictors of injuries among senior soccer players. A prospective study. J Sports Sci Med 2010;9.

12 Ö K, Aoki H, Goedhart E, et al. Severe musculoskeletal time-loss injuries and symptoms of common mental disorders in professional soccer: a longitudinal analysis of 12-month follow-up data. Knee Surg Sports Traumatol Arthrosc 2018:26:946-54.

13 Leach LS, Christensen H, Mackinnon AJ, et al. Gender differences in depression and anxiety across the adult lifespan: the role of psychosocial mediators. Soc Psychiatry Psychiatr Epidemiol 2008:43:983-98.

14 Rocha VVS, Osório FdeL, FdL O. Associations between competitive anxiety, athlete characteristics and sport context: evidence from a systematic review and metaanalysis. Arch Clin Psychiatry 2018;45:67-74.

15 Swann C, Moran A, Piggott D. Defining elite athletes: issues in the study of expert performance in sport psychology. Psychol Sport Exerc 2015;16:3-14.

16 Rice SM, Parker AG, Rosenbaum S, et al. Sport-related concussion and mental health outcomes in elite athletes: a systematic review. Sports Med 2018;48:447-65.

17 Dingemans $E$, Henkens K. How do retirement dynamics influence mental well-being in later life? A 10-year panel study. Scand J Work Environ Health 2015;41:16-23.

18 Joanna Briggs Institute. Critical appraisal tools. Secondary critical appraisal tools, 2017. Available: http://joannabriggs.org/research/critical-appraisal-tools.html

19 Biostat. Comprehensive meta-analysis. Version 3.3.070 [program]. Englewood, NJ: Biostat. 2014.

20 Rosenthal R, DiMatteo MR. Meta-analysis: recent developments in quantitative methods for literature reviews. Annu Rev Psychol 2001:52:59-82.

21 Peterson RA, Brown SP. On the use of beta coefficients in meta-analysis. J App/ Psychol 2005:90:175-81.

22 Valentine JC, Pigott TD, Rothstein HR. How many studies do you need? A primer on statistical power for meta-analysis. J Edu Behav Stat 2010;35:215-47.

23 Borenstein M, Hedges LV, Higgins JPT, et al. Comprehensive meta analysis version 3.0. Englewood, NJ: Biostat, 2004: 1-97.

24 Higgins J.P.T, Green S.Cochrane handbook for systematic reviews of interventions. Version 5.1.0 [updated March 2011] The Cochrane Collaboration. 2011.

25 Borenstein M, Hedges LV, Higgins JP, et al. Introduction to meta-analysis. West Sussex, UK: John Wiley \& Sons, 2011.

26 Borenstein M, Higgins JPT, Hedges LV, et al. Basics of meta-analysis: $I^{2}$ is not an absolute measure of heterogeneity. Res Synth Methods 2017;8:5-18
27 Duval S, Tweedie R. Trim and fill: a simple funnel-plot-based method of testing and adjusting for publication bias in meta-analysis. Biometrics 2000;56:455-63.

28 Rothstein HR, Sutton AJ, Borenstein M. Publication bias in meta-analysis: prevention, assessment and adjustments. John Wiley \& Sons, 2006.

29 Brand R, Wolff W, Hoyer J. Psychological symptoms and chronic mood in representative samples of elite student-athletes, deselected student-athletes and comparison students. School Mental Health 2013;5:166-74.

30 Filaire $E$, Le Scanff C, Duché $P$, et al. The relationship between salivary adrenocortical hormones changes and personality in elite female athletes during handball and volleyball competition. Res Q Exerc Sport 1999;70:297-302.

31 Gerber M, Holsboer-Trachsler E, Pühse U, et al. Elite sport is not an additional source of distress for adolescents with high stress levels. Percept Mot Skills 2011:112:581-99.

32 Fiorilli G, Iuliano E, Aquino G, et al. Mental health and social participation skills of wheelchair basketball players: a controlled study. Res Dev Disabil 2013;34:3679-85.

33 Junge $A$, Feddermann-Demont N. Prevalence of depression and anxiety in top-leve male and female football players. BMJ Open Sport Exerc Med 2016;2:e000087.

34 Weber ML, Dean J-HL, Hoffman NL, et al. Influences of mental illness, current psychological state, and concussion history on baseline concussion assessment performance. Am J Sports Med 2018c;46:1742-51.

35 Gulliver A, Griffiths KM, Mackinnon A, et al. The mental health of Australian elite athletes. J Sci Med Sport 2015;18:255-61.

36 Ivarsson A, Johnson U, Podlog L. Psychological predictors of injury occurrence: a prospective investigation of professional Swedish soccer players. I Sport Rehabil 2013;22:19-26

37 Lancaster MA, McCrea MA, Nelson LD. Psychometric properties and normative data for the brief symptom Inventory-18 (BSI-18) in high school and collegiate athletes. Clin Neuropsychol 2016:30:321-33.

38 Weber S, Puta C, Lesinski M, et al. Symptoms of anxiety and depression in young athletes using the hospital anxiety and depression scale. Front Physiol 2018a;9:1-12.

39 Sheehan RB, Herring MP, Campbell MJ. Longitudinal relations of mental health and motivation among elite student-athletes across a condensed season: plausible influence of Academic and athletic schedule. Psychol Sport Exerc 2018b;37:146-52

40 Yang J, Peek-Asa C, Corlette JD, et al. Prevalence of and risk factors associated with symptoms of depression in competitive collegiate student athletes. Clin J Sport Med 2007:17:481-7.

41 Foskett RL, Longstaff F. The mental health of elite athletes in the United Kingdom. J Sci Med Sport 2018:21:765-70.

42 Junge A, Prinz B. Depression and anxiety symptoms in 17 teams of female football players including 10 German first League teams. Br J Sports Med 2018.

43 Byrd M, Dixon CE, Lucke-Wold B. Examining the correlation between acute behavioral manifestations of concussion and the underlying pathophysiology of chronic traumatic encephalopathy: a pilot study. J Neurol Psychol 2018;6.

44 Gouttebarge V, Aoki H, Lambert M, et al. A history of concussions is associated with symptoms of common mental disorders in former male professional athletes across a range of sports. Phys Sportsmed 2017a;45:443-9.

45 Weber M, Lynall R, Hoffman N, et al. Health-related quality of life following concussion in collegiate student-athletes with and without concussion history. Ann Biomed Eng 2018b:1-11.

46 Yang J, Peek-Asa C, Covassin T, et al. Post-concussion symptoms of depression and anxiety in division I collegiate athletes. Dev Neuropsychol 2015;40:18-23.

47 Gouttebarge V, Frings-Dresen MHW, Sluiter JK. Mental and psychosocial health among current and former professional footballers. Occup Med 2015b;65:190-6.

48 Gouttebarge V, Tol JL, Kerkhoffs GMMJ. Epidemiology of symptoms of common mental disorders among elite Gaelic athletes: a prospective cohort study. Phys Sportsmed 2016d:44:283-9.

49 Johnson U, Ivarsson A. Psychological predictors of Sport injuries among junior soccer players. Scand J Med Sci Sports 2011:21:129-36.

50 Gouttebarge $V$, Jonkers $\mathrm{R}$, Moen $\mathrm{M}$, et al. The prevalence and risk indicators of symptoms of common mental disorders among current and former Dutch elite athletes. J Sports Sci 2017d;35:2148-56.

51 Gouttebarge V, Kerkhoffs GMMJ. A prospective cohort study on symptoms of common mental disorders among current and retired professional ice hockey players. Phys Sportsmed 2017e;45:252-8.

52 Gouttebarge V, Backx FJG, Aoki H, et al. Symptoms of common mental disorders in professional football (soccer) across five European countries. J Sports Sci Med 2015a;14:811-8.

53 Gouttebarge V, Aoki H, Kerkhoffs GM. Prevalence and determinants of symptoms related to mental disorders in retired male professional footballers. J Sports Med Phys Fitness 2016a; 56:648-54.

54 Gouttebarge V, Kerkhoffs G, Lambert M. Prevalence and determinants of symptoms of common mental disorders in retired professional Rugby Union players. Eur J Sport Sci 2016c;16:595-602.

43 Du Preez EJ, Graham KS, Gan TY, et al. Depression, anxiety, and alcohol use in elite rugby league players over a competitive season. Clin J Sport Med 2017;27:530-5.

56 Brown JC, Kerkhoffs G, Lambert MI, et al. Forced retirement from professional rugby union is associated with symptoms of distress. Int J Sports Med 2017;38:582-7. 
57 Gouttebarge V, Aoki H, Verhagen EALM, et al. A 12-month prospective cohort study of symptoms of common mental disorders among European professional footballers. Clin J Sport Med 2017b;27:487-92.

58 Gouttebarge V, Hopley P, Kerkhoffs G, et al. Symptoms of common mental disorders in professional rugby: an international observational descriptive study. Int J Sports Med 2017c;38:864-70.

59 Gouttebarge V, Hopley P, Kerkhoffs G, et al. A 12-month prospective cohort study of symptoms of common mental disorders among professional rugby players. Eur J Sport Sci 2018;18:1004-12.

60 Schuring N, Aoki H, Gray J, et al. Osteoarthritis is associated with symptoms of common mental disorders among former elite athletes. Knee Surg Sports Traumatol Arthrosc 2017;25:3179-85.

61 Ö K, Johnson U, Kerkhoffs GM, et al. The global burden of mental, neurological and substance use disorders: an analysis from the of Disease Study 2010. Plos One 2015; 10:e0116820.

62 Guillén F, Sánchez R. Competitive anxiety in expert female athletes: sources and intensity of anxiety in National Team and First Division Spanish basketball players. Percept Mot Skills 2009;109:407-19.

63 Cromer L, Kaier E, Davis J, et al. OCD in college athletes. AJP 2017:174:595-7.

64 Kang KD, Hannon JC, Harveson A, et al. Perfectionism and burnout in women professional golfers. J Sports Med Phys Fitness 2016;56:1077-85.

65 Han DH, Kim BN, Cheong JH, et al. Anxiety and attention shifting in professional baseball players. Int J Sports Med 2014;35:708-13.

66 Sheehan RB, Herring MP, Campbell MJ. Associations between motivation and menta health in sport: a test of the hierarchical model of intrinsic and extrinsic motivation. Front Psychol 2018a;9.

67 Eissa MF, Hendawy HF, Mahmoud DAM, et al. The relationship between coping profile and Axis-I psychiatric morbidity in athletes. Middle East Current Psychiatry 2018;25:72-83.

68 Shacham S. A shortened version of the profile of mood states. J Pers Assess 1983;47:305-6.

69 Moore RD, Sauve W, Ellemberg D. Neurophysiological correlates of persistent psycho-affective alterations in athletes with a history of concussion. Brain Imaging Behav 2016;10:1108-16.

70 Petito A, Altamura M, luso S, et al. The relationship between personality traits, the $5 \mathrm{HTT}$ polymorphisms, and the occurrence of anxiety and depressive symptoms in elite athletes. PLoS One 2016;11:e0156601.

71 Wilson PB, Madrigal LA. Associations among omega-3 fatty acid status, anxiety, and mental toughness in female collegiate athletes. J Am Coll Nutr 2017:36:602-7.

72 Morgan WP, O'Connor PJ, Ellickson KA, et al. Personality structure, mood states, and performance in elite male distance runners. Int J Sport Psychol 1988;19:247-63.

73 Halvari H, Gjesme T. Trait and state anxiety before and after competitive performance. Percept Mot Skills 1995;81(3 Pt 2):1059-74.

74 Bartholomew J. Psychological states following a maximal exercise test: the impact of manipulated performance feedback in competitive athletes. Int J Sport Psychol 2003:34:240-54

75 Turner PE, Raglin JS. Variability in precompetition anxiety and performance in college track and field athletes. Med Sci Sports Exerc 1996:28:378-85.

76 Levit $\mathrm{M}$, Weinstein A, Weinstein Y, et al. A study on the relationship between exercise addiction, abnormal eating attitudes, anxiety and depression among athletes in Israel. J Behav Addict 2018;7:800-5.

77 Ströhle A. Sports psychiatry: mental health and mental disorders in athletes and exercise treatment of mental disorders. Eur Arch Psychiatry Clin Neurosci 2018:1-14.

78 Taher D, Mahmud N, Amin R. The effect of stressful life events on generalized anxiety disorder. European Psychiatry 2015:30.

79 Ryum T, Kennair LEO, Hjemdal 0, et al. Worry and metacognitions as predictors of anxiety symptoms: a prospective study. Front Psychol 2017:8.

80 Fava GA, Sonino N. The biopsychosocial model thirty years later. Psychother Psychosom 2008:77:1-2.

81 Wiese-Bjornstal DM. Psychology and socioculture affect injury risk, response, and recovery in high-intensity athletes: a consensus statement. Scand J Med Sci Sports 2010;20:103-11

82 Gorczynski PF, Coyle M, Gibson K. Depressive symptoms in high-performance athletes and non-athletes: a comparative meta-analysis. Br J Sports Med 2017;51:1348-54.

83 Rice SM, Purcell R, De Silva S, et al. The mental health of elite athletes: a narrative systematic review. Sports Med 2016;46:1333-53.

84 Menon R. Sports psychiatry - the lack of an Australian narrative. Aust N Z Psychiatry 2016;50:197-8.

85 Reardon CL, Factor RM. Sport psychiatry. Sports Medicine 2010;40:961-80.

86 Burns L, Weissensteiner JR, Cohen M. Lifestyles and mindsets of Olympic, Paralympic and world champions: is an integrated approach the key to elite performance? $\mathrm{Br} J$ Sports Med 2018

87 Kessler RC, Berglund P, Demler O, et al. Lifetime prevalence and age-of-onsetAgeof-Onset distributions of DSM-IV disorders in the National Comorbidity Survey Replicationcomorbidity survey replication. Arch Gen Psychiatry 2005;62:593-602.
88 Whiteford HA, Ferrari AJ, Degenhardt L, et al. The global burden of mental, neurological and substance use disorders: an analysis from the of Disease Study 2010. Plos One 2015;10:e0116820.

89 Rickwood DJ, Deane FP, Wilson CJ. When and how do young people seek professional help for mental health problems? Med J Aust 2007;187.

90 Gulliver A, Griffiths KM, Christensen H. Barriers and facilitators to mental health help-seeking for young elite athletes: a qualitative study. BMC Psychiatry 2012;12.

91 Rickwood D, Paraskakis M, Quin D, et al. Australia's innovation in youth mental health care: the headspace centre model. Early Interv Psychiatry 2018.

92 Donohue B, Gavrilova Y, Galante M, et al. Controlled evaluation of an optimization approach to mental health and sport performance. J Clin Sport Psychol 2018:12:234-67.

93 Hunt M, Auriemma J, Cashaw ACA. Self-report bias and underreporting of depression on the BDI-II. J Pers Assess 2003:80:26-30.

94 Gross M, Moore ZE, Gardner FL, et al. An empirical examination comparing the Mindfulness-Acceptance-Commitment approach and psychological skills training for the mental health and sport performance of female student athletes. Int J Sport Exerc Psychol 2018;16:431-51.

95 Millet GP, Groslambert A, Barbier B, et al. Modelling the relationships between training, anxiety, and fatigue in elite athletes. Int J Sports Med 2005;26:492-8.

96 Doherty S, Hannigan B, Campbell MJ. The experience of depression during the careers of elite male athletes. Front Psychol 2016;7.

97 Rice SM, Kealy D, Oliffe JL, et al. Externalizing depression symptoms among Canadian males with recent suicidal ideation: a focus on young men. Early Intervention in Psychiatry 2018;39.

98 Rice SM, Purcell R, McGorry PD. Adolescent and young adult male mental health: transforming system failures into proactive models of engagement. J Adolesc Health 2018;62:S9-S17.

99 Cavanagh A, Wilson CJ, Kavanagh DJ, et al. Differences in the expression of symptoms in men versus women with depression: a systematic review and metaanalysis. Harv Rev Psychiatry 2017;25:29-38.

100 Rice SM, Fallon BJ, Aucote HM, et al. Development and preliminary validation of the male depression : furthering the assessment of depression in men. J Affect Disord 2013:151:950-8

101 Gorczynski PF, Brittain DR. Call to action: the need for an LGBT-focused physical activity research strategy. Am J Prev Med 2016:51:527-30.

102 Cokley K, Hall-Clark B, Hicks D. Ethnic Minority-Majority status and mental health: the mediating role of perceived discrimination. J Ment Health Couns 2011;33:243-63.

103 Nixdorf I, Frank R, Beckmann J. Comparison of athletes' proneness to depressive symptoms in individual and team sports: research on psychological mediators in junior elite. Front Psychol 2016;7.

104 World Anti-Doping Agency. Prohibited list. Montreal:WADA, 2019

105 Çelebi MM, Başkak B, Saka T, et al. Psychiatric and functional evaluation of professional athletes following anterior cruciate ligament reconstruction. Acta Orthop Traumatol Turc 2015:49:492-6.

106 Drew M, Vlahovich N, Hughes D, et al. Prevalence of illness, poor mental health and sleep quality and low energy availability prior to the 2016 Summer Olympic Games. Br J Sports Med 2018;52:47-53.

107 Gomez-Piqueras P, González-Víllora S, Grassi A, et al. Are we making smart decisions regarding return to training of injured football players? preliminary results from a pilot study. IES 2018;26:115-23.

108 Gleeson M, McDonald WA, Pyne DB, et al. Salivary IgA levels and infection risk in elite swimmers. Med Sci Sports Exerc 1999:31:67-73.

109 Gouttebarge V, Aoki H, Verhagen E, et al. Are level of education and employment related to symptoms of common mental disorders in current and retired professional footballers? Asian J Sports Med 2016b;7:e28447

110 Guo J, Yang J, Yi H, et al. Differences in postinjury psychological symptoms between collegiate athletes with concussions and orthopedic injuries. Clin J Sport Med 2018. doi:10.1097/JSM.0000000000000621. [Epub ahead of print: 21 Jun 2018].

111 Selmi O, Ben khalifa W, Zouaoui M, et al. High intensity interval training negatively affects mood state in professional athletes. Sci Sports 2018;33:e151-7.

112 Houltberg BJ, Wang KT, Qi W, et al. Self-narrative profiles of elite athletes and comparisons on psychological well-being. Res Q Exerc Sport 2018:89:354-60.

113 Liu X, Yang X, Hou Z, et al. Increased interhemispheric synchrony underlying the improved athletic performance of rowing athletes by transcranial direct current stimulation. Brain Imaging Behav 2018:1-9.

114 Kilic Özgür, Aoki H, Haagensen R, et al. Symptoms of common mental disorders and related stressors in Danish professional football and handball. Eur J Sport Sci 2017:17:1328-34.

115 van Ramele S, Aoki H, Kerkhoffs GMMJ, et al. Mental health in retired professional football players: 12-month incidence, adverse life events and support. Psychol Sport Exerc 2017;28:85-90 